\title{
Determinants of Sea Gypsies School Leavers in the Philippines
}

\author{
Limuel Abelgas ${ }^{1}$, Edwin Pilapil ${ }^{2}$, Jonathan O. Etcuban ${ }^{3}, J_{a n i n e} J_{0 y}$ Tenerife $^{4}$, Lilibeth Pinili ${ }^{5}$ and Regina Sitoy ${ }^{6}$ \\ ${ }^{1,2,3,4,5 \& 6}$ Faculty, Cebu Technological University, Cebu City, Philippines \\ E-Mail: joetcuban@gmail.com
}

\begin{abstract}
The Sea Gypsies (Badjaos) stride in education since a large number of children not taking part in education programmes. This is due to reasons of an unjustified stigma associated with the Badjao people, which cause them to be discriminated against in school and the employment market. This study ascertained the determinants of Badjao school leavers in Cebu City, Philippines. It employed a descriptive method using the adapted survey questionnaire. Sixty-five respondents were identified using purposive sampling. The data gathered were organized and treated statistically using weighted mean, percentile ranking, and multiple regression. The findings disclosed that the Badjao respondents had perceived that personal and family factors could be the determinants why they had left school. Also, the integration and program implementation were not associated with why the respondents had left school. The respondents' profile and their perceived reasons for leaving school had no significant relationship. Lastly, the respondents perceived reasons for leaving school. Hence, it is highly recommended that the proposed developmental plan of this study be adopted, implemented and monitored in order to help the Badjaos to finish their studies and become more responsible and productive citizens of the country.

Keywords: Sea Gypsies, School Leavers, Social Integration
\end{abstract}

\section{INTRODUCTION}

The United Nations believes that providing a quality education serves as a backbone in helping people to escape from poverty and attain continuous economic growth. While significant progress in the Philippines has been made towards increasing access to education at all levels and increasing enrolment and promotion rates in schools, but still, an inconvenient truth continues to bother the government for noticeably, there are many indigenous people who still hardly make it finish even the primary education despite the bolder efforts done to make more significant strides for achieving universal education goals.

Substantially, the Philippines are known to be a sanctuary of indigenous people whose population has approximately gone, composed of 110 ethno linguistic groups. They slowly occupy Northern Luzon and Mindanao, with some groups in the Visayas area. The Philippine Constitution acknowledges this diversity and so guarantees to uphold the rights of Indigenous Peoples and promotes their welfare. In congruence, Republic Act 8371, otherwise known as the "Indigenous Peoples Rights Act of 1997", is enacted to fulfill the mandate vested by the constitution. In Cebu City, at least 1,468 households were identified to be those of indigenous people as of 2015. Many of these are members of the Badjao tribe are living in a 5,600-square meter community in New Alaska Beach Association (NABA), the name given to an urban settlement near the shore of Mambaling village, Cebu City, Philippines. The Badjaos diaspora in Cebu City was caused by discrimination abuses of the rebels and the endless war in Mindanao between the rebellious groups and the armed forces of the government. However, the Badjao tribe as they inevitably socialized into their neighborhood and immersed themselves in school, the members of the larger society had criticized, mocked, laughed and disrespected them. The Badjao students are allegedly evaded in schools by their classmates. They are called as moklo (naive), hugawan (untidy), bahongdagat (smell-like sea), tapulan (lazy), and bogo (dull).

Based on the 2017 Learners' Information System of the Department of Education, Cebu City Division, the Badjaos enrollment rate in elementary to secondary education has been steadily declining, with an annual decrease average of $5.67 \%$ and an annual drop-out rate of $3.1 \%$. If this trend goes on, it can be projected that the future next generation of the Badjaos might not have economic alleviation. Instead, they might remain jobless or have a meager income that may lead to intergenerational poverty. Undeniably, the Badjaos need to be educated for gainful employment, have better management have their know small-scale businesses and gain other means of livelihood.

In Cebu City, the coastal areas that the Badjaos used to park and anchor their pump boats are already made as reclamation properties. This could cause economic displacement. For these indigenous people to cope up and overcome the challenges of the new environment they have been settling with, finishing primary education or getting a college degree is a great leap to do. Hopefully, by accomplishing this, it can draw a line for the Badjaos from being beggars on the streets and the sea, having a one-dayone-eat scenario, experiencing societal outcast and marginalization, being dependent on the government social services. Those were the causes of why this study was conceptualized off. This study ascertained the different determinants that drove the Badjaos from leaving school; evaluate the different programs done by some of the government agencies for the Badjaos, and treat if these have a significant relationship why Badjaos leave school. Whatever the findings, this study would propose a developmental plan anchored at helping the Badjao students and community for the betterment of their lives. 
This study supposed that Badjaos leave from school because of family, personal, social integration factors and the lack of sustainably regular government programs that aim at uplifting the Badjao tribe. After decades of co-existence with the majority population of Cebu City, there is a sharp distinction between Badjao and their neighbors -- when it comes to settlements, clothes, language, traditions, and livelihood. Indeed, Badjao can even hardly finish primary education; find a job as they are seen as dirty, noisy and uncivilized.

This display of the superiority of the dominant class against the minority social groups gives birth to Cultural Hegemony Theory as advocated by Antonio Gramsci (Fry, 2003). Cultural hegemony is a phenomenon where the majority groups impose its superiority upon the minority. In result, the minority develops an inferiority complex whereby they no longer do something about it. Instead, they think that there is no way to get away with it, Molintas (2004). In society, hegemony becomes present when the minority accepts the unpleasant societal interactions done by the majority groups.

HoSang (2010) highlighted that the worse effect of hegemony is when the majority are proud of their discriminating actions and that the minority is already confined with the idea that they are indeed inferior. The unconscious but worst effect of cultural hegemony is it imposes towards the minority groups mind that they are meant to be treated that way and so they embrace it and develop no propositions or resistance for they think it is the way things should be. The concept of the impossibility to change the status quo is already developed and remains in the minority's minds and actions (Drayton, (2009). Although hegemony undergoes complex processes, the fact remains that the superiority complex of the majority may result in discrimination and marginalization to the minority. This will always be in control and become part of the society's cultural atmosphere that may result in slow economic growth in general (Brookfield, 2005).

The theory discusses why Badjaos as part of the cultural minority are mistreated. The Aetas also experience such societal marginalization in Luzon. They have never been acculturated and can preserve who they were centuries ago, still experience discrimination because of their color, customs, culture, and tradition. As a result, they decided to stay in the higher altitude of the mountains as a form of resistance to lowlanders (Macalandag et al., 2009). Secondly, though Muslim is labeled as the most significant minority, they are not excluded from unfairness. Study reveals that when Muslim people (wearing the Muslim garments) apply for a job they tend to get shorter interactions and very least probability of being hired due to the stigma that Muslim individuals are almost always categorically associated to rebellious groups.

All of these facts are manifestations that there has been a silent but noticeable inequality imposed to indigenous cultural minorities, despite the existence of the Indigenous People's Rights Act (IPRA) of 1997, section 1, paragraph d, mandating that the State will ensure that individuals from the ICCs/IPs paying little mind to sex, will similarly appreciate the full proportion of human rights and opportunities without qualification or separation. Marginalization and discriminations are caused by lack of knowing and understanding other people. Understanding the nature of a group or an individual is necessary to stop judging others based on one's standard. A colossal chance among the members of the society to treat others kindly if they happen to fully be aware of that we have our uniqueness and identities as groups and individuals. Commencing to be kind in dealing with all types of people from all walks of life, without resorting to any form of discrimination and oppression, would result in a more productive society and progressive country

According to Charon and Cahill (1979) that no culture, race or group is ever superior. We humans have unique interpretations and perspectives, which are often influenced by the society we belong to. Ideas, practices, and judgments are best understood by the society where somebody or a group resides. Thus, judging others based on the standard and norm that somebody has in his society would produce chaotic results.

Ethnicity is an aspect by which a man identifies with his ethnic group with which he shares cultural, religious, linguistic, behavioral and biological features (Smedly \& Smedley, 2005; Young, 2005; Rogoff, 2003). Right since the old age until recent times, the Philippines has been populated by people of various ethnicity. This has resulted in this country to become the home of many different ethnic groups. The 175 ethno linguistic groups of the Philippines, each with its language, identity, culture, and history serve as living evidence of how complex, diverse and colorful the former is (Macalandag, 2009). These compound uniqueness of identities must not be a hindrance, instead, be an asset of realizing the common goals of the state that are all anchored in pushing the country towards its great potential in order to uplift the lives of each Filipino.

The Philippines' progress undoubtedly rests on the quality of education accessible to its citizenry and the propriety of its consummation. In every educational system, all the persons involved such as administrators, teachers, students, parents, and other stakeholders play different significant roles in molding the learners. This capitalizes that the best form of resources is humans, for the latter is the active player who does all the necessary works so that a nation can achieve its full holistic potential and continually give more sustainable and quality services to its general public. It is said that in every classroom door opens. It helps to close the intergenerational poverty chain. However, if students do not continue their studies, it produces opposite outcomes.

The Philippines has the friendliest people on earth and has been tagged as a sanctuary of several indigenous people; 
avast of them are treated fairly and squarely, but the silent few may not have been. Macalandag (2009) stated that there is a lot of cultural minorities in the Philippines which has been marginalized, discriminated, oppressed and neglected. One of those is the Badjao. The Badjaos are always linked with laziness because, as commonly believed, they would instead beg than work for money. While it may be true that there are some of them who actually ask for money but many of them as well continue to strive to earn a living by becoming pearl merchants (they have an enduring supply of refined pearls from Palawan and Mindanao), sell fruits and food in their community just to augment the family's income.

The Badjaos never really had comfortable lives, when they were all the while living adrift; they were at any rate free from the regular dismissal and hardship brought upon by different clans that live ashore. These watchmen of the ocean have encountered themselves that circumstances are complicated on the water, yet more terrible ashore. At present, the Badjaos are the most minimized ethnic gathering and one of the least fortunate clans in the Philippines, a Muslim clan that is avoided by nearly everybody, for as needs are, the Badjaos are typically viewed as unhygienic, ignorant and inept (Reyes, 2014).

It has been over five decades since the Badjaos left Zamboanga, yet they still are considered as the poorest among the poor in the Philippines. This could be the results of displacement from their place of origin (sea to land), their livelihood is traditionally and totally dependent on the sea resources for in the latter, since consciousness strike in their mind, they have lived, dived, fished, and rarely setting foot on land, illiteracy for lack of interest in education, which would have been an instrument towards self-realization and self-actualization; and low-self-esteem because of constant marginalization by the majority.

Most Badjaos often are seen on the streets as mendicants as they try hard to survive with the modern way of life in the city. Begging money is never an embarrassment for them because the Badjaos consider it as a job, it is reasonable to do it, and they do not know that it is against some city ordinances. Badjao students sneak out from their classes, due to hunger and command of their parents, and go to the streets to fill an empty stomach. It is undeniable that one's nutrition plays a significant role to have an excellent performance in school.

The Philippines' Department of Education (Dep. Ed) revealed that for the past five years (2011-2016) the national cohort survival rate of elementary indigenous pupils' percent in the elementary level had been steadily declining annually. The decrease is much more significant in the secondary level for, in the same years mentioned above, the indigenous high students' cohort survival rate was only $8 \%$. This means that as they continue to the next grade level, many of the indigenous students stop their studies and are not able to complete the primary education. Based on Dep.
Ed Learners Information System, Badjaos have low participation, promotion, and cohort survival rates, but high in dropout and failure rates resulting in meager cohort survival rate. The country's 2015 census revealed that of the $2 \%$ indigenous people, $46 \%$ of them are elementary graduates, $19 \%$ are secondary graduates and $18 \%$ of them with no education at all. A mere $1.76 \%$ of them enrolled in college, and only about $1.1 \%$ graduated college. Making use of these as baseline information, it can be deduced that indigenous people are far no better off given that they are more marginalized and vulnerable. Students from racial/ethnic minority backgrounds are disproportionately affected by discrimination, with negative impacts for academic performance.

Badjaos have difficulty in finishing their studies because of the environment they have been immersed with. Their elders are still not able to move on from the things they got used with where they left almost six decades back for. They were robbed and abused. Badjaos need to realize that their culture remains as it is, even if they do income generation ways that are more appropriate to their existing environment, it can even alleviate their lives towards a tremendous promising future. If this trend continues, it can be predicted that, regardless of how many years will pass, this minority group would face the same challenges and be not able to attain economic progress.

According to Pathania et al., (2005), their enrolment rate continually decreases. It is difficult for a Badjao child to complete the grade level within a year because the parents take their children to the streets or sea for begging; there is no food, or they are not motivated to continue for many of them are severely bullied in school. Hohepa et al., (2006) substantiated that physical distance should not be the only factor in accessibility to education; psychological concerns should also be considered. Rigby (2004) says that indigenous children and youth are frequent victims of discrimination and bullying at schools. Monks and Smith (2006), Many children had painful experiences of being bullied and discriminated both at the primary and tertiary education levels. In most cases, the children endure the bullying although it hurts them. Being discriminated and bullied were the most hurtful experiences that they ever had in their lives. Aside from the devastating emotional impact, it pushed them to drop out of school.

Discrimination against indigenous people is a structural problem, which fundamentally hinders their appropriate access to essential services, resources, and opportunities. Indigenous children are more likely to suffer from discrimination in school by not only the classmates but also the teachers. Their right to self-determination, cultural integrity and diversity need to be recognized. Efforts should start with the process of changing mindset and behavior of government personnel, including schoolteachers, at nearby and national dimension just as school education for both indigenous and non-indigenous children. Their ages might have caused the diminution above of Badjaos' educational 
participation, for those students who stop for a year or more have the feeling of being left behind by their contemporary, this results to a feeling of shame. Since the Badjaos men are commanded to earn a living by swimming for alms, diving and selling pearls, the young Badjao ladies are permitted by the parents to marry at a young age. A handful number of siblings being taken care of by the school-aged Badjaos cause them to lose their focus on their studies.

Notwithstanding, it is beneficial to take note of that the Bajaos' segregation adventure still keeps on happening as of late. A few occupants of Mambaling town grumbled that their place is not just a dumping ground of trash, yet in addition to the Bajaos. They think the Bajaos are grimy; they called them squatters and homeless people. They blamed them for taking from and pestering natural product merchants and bystanders. Many of the Badjaos are even called there as "Moklo" a Cebuano term that means "bogo or oplok" (incredibly dull).

In Cebu City streets, the Badjaos risk their lives by asking for alms; and in the ports, it is also common that Badjao children dive for coins. While the passenger on ferries, who view it as a form of entertainment, throw coins to them. The Bajao students were mocked and being avoided in school, which might be one of the reasons why they are not interested in being in school anymore.

The challenges enumerated above pushed harder the government's efforts in crafting and implementing programs to uplift the lives of the indigenous people, such as Conditional Cash Transfer Program, the Educational and Financial Assistance Program of National Commission for Indigenous People, and the Alternative Learning System and Localization and Contextualization of Instructional Materials of Dep. Ed. All of these are the reasons why this study was formulated. This examined the different factors that push the Badjaos in Cebu City, Philippines to discontinue their study. The related literature and studies cited to establish a framework that motivates and guides the further exploration of the possible determinants why many of the Badjaos do not or cannot continue to finish even their secondary education. This undertaking hopes to unlock some unseen but existing problems of this indigenous tribe for them to improve their quality of life.

\section{OBJECTIVES OF THE STUDY}

This research ascertained the determinants of Badjao school leavers in Barangay Mambaling, Cebu City, Philippines. It answered the: 1) Profile of the respondents; 2) Reasons for leaving from school; 3) Significant relationship between the profile of the respondents and their perceived reasons for leaving from school.

\section{METHODOLOGY}

This study had employed the descriptive correlational methodin which its purpose is to establish the facts that would enrich the quantity and quality of information, create new concepts, or produce more discernment that would unfold causations and relationships to formulate appropriate interventions of the known gaps and problems. The study was conducted in Mambaling village, Cebu City in which there were 1,485 Badjao residents. The respondents were the 65 Badjaos who were not able to continue their secondary education. They are selected using nonprobability purposive sampling technique. The researchers utilized a survey questionnaire, which was composed of three parts. Part I contains the profile of the respondents, which contains family, personal and social integration factors. Part II covers the reasons for the respondents of leaving from school statements. Part III is a fully researcher-made survey questionnaire in which the statements were derived from respondents' felt and known programs of the identified government agencies to capture the extent of its programs implemented. The gathered data were treated using frequency, weighted mean, and multiple regressions.

\section{RESULTS AND DISCUSSION}

A. Profile of the Respondents: This section presents the profile of the respondents in terms of their family, personal and integration factors. Moreover, these factors were determined through their sub-components. The family factor was an important variable that is considered in this study, which could explain why the respondents leave from school. This factor was determined through the family size, parents' highest educational attainment, parents' occupation, combined family monthly income, and parental support that the respondents received. This family size was included in this study for it played a significant role in some of the studies related to dropping out of school. The results of the data gathered are presented in Table I.

TABLE I FAMILY SiZE AND COMBINED FAMILy INCOME OF PARENTS $(\mathrm{N}=65)$

\begin{tabular}{|l|c|c|}
\hline \multicolumn{3}{|c|}{ A. Family Size } \\
\hline More than 10 & 13 & 20.00 \\
\hline $6-10$ & 45 & 69.23 \\
\hline $1-5$ & 7 & 10.77 \\
\hline Average : & 8 & Percentage \\
\hline \multicolumn{2}{|c|}{ B. Combined Family Income (in PhP) } \\
\hline Less than P 7,890 & 65 & 100.00 \\
\hline
\end{tabular}

As reflected in Table I, the most dominant figure of family size 6 to 10. This had caused to have an average family size of 8 persons per family. Given the fact the all of the family members needed to have their daily basic needs, this size, therefore, might be a determinant why the Badjaos leave from school.

Family size influenced children's schooling cycle greatly. In comparison to children with fewer siblings, children with more siblings tend to enroll later, repeat grades more often 
and drop out of school earlier. Consequently, with larger family size, the financial burden/potential workload was more significant; children were less likely to attend school and often drop out. Similarly, a study found that having a large number of siblings which more than six children were associated with a $36 \%$ increase in the odds of dropping out from school, in comparison to the odds for smaller families (Eloundou, 2000).

On the combined family income, this clearly showed that the Badjao respondents could have been facing financial insufficiency daily that may result in poor nutrition or not having an allowance for school at all. Considine and Zappala (2002) stated that children who hailed from less or low-income parents had resulted to low literacy level, low retention rate, problems in school behavior and more difficulty in their studies and mostly displayed negative attitude towards studies and school. These findings were corroborated by Eamon (2005) which specified that those learners usually from low socio-economic status or area showed low performance academically and got low scores as compared to the other students whose parents had a considerably good income. The parents' highest educational attainment was taken into consideration as well for some studies had mentioned this to be a possible determinant of leaving from school.

TABLE II EduCATION AND OCCUPATION OF THE ReSPONDENTS' PARENTS $(\mathrm{N}=65)$

\begin{tabular}{|c|c|c|c|c|}
\hline & \multicolumn{2}{|c|}{ Mother } & \multicolumn{2}{|c|}{ Father } \\
\hline & 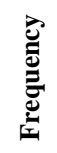 & 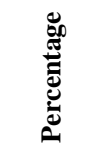 & 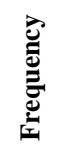 & 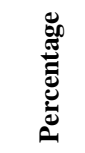 \\
\hline \multicolumn{5}{|c|}{ A. Education of Parents } \\
\hline $\begin{array}{l}\text { High School } \\
\text { Graduate }\end{array}$ & 1 & 2.00 & 1 & 2.00 \\
\hline Elementary Graduate & 64 & 98.00 & 64 & 98.00 \\
\hline \multicolumn{5}{|c|}{ B. Occupation } \\
\hline Housewife /Husband & -- & -- & 58 & 89.23 \\
\hline Fisherman & 58 & 89.23 & -- & -- \\
\hline Vendor & 5 & 7.69 & 6 & 9.23 \\
\hline Small Business & 2 & 3.08 & & \\
\hline Large Business & -- & -- & 1 & 1.54 \\
\hline
\end{tabular}

As shown in the table II, an overwhelming $98 \%$ of the respondents' parents had attended elementary education. This could be interpreted that even in almost 70 years of residing in Cebu City, the Badjaos indeed have difficulty in finishing the primary education despite the nearness of the elementary and secondary schools in the area. Meanwhile, parents undeniably always served as our guidance and source of wisdom, especially during formative years. Given the data above, it was most likely to happen that when the parents were not exposed to higher education, it could influence the discontinuation of children in school. As explained by Ainsworth et al., (2005), higher parental education was related to expanded access to training, higher participation rates, and lower dropout rates. Guardians, who had accomplished a specific instructive dimension, may need their kids to accomplish in any event a similar dimension (Grant \& Hallman, 2008).

On the occupations of the parents, the data manifested that the Badjaos were indeed dependent on the seas as their primary way of earning a living. However, noticeably few of the husbands had begun to engage in selling or running a micro business. Lareau (2003) explained that the occupation of the students' parents played a significant role in the students' academic performance indirectly. Its effect was indirect for it was part of the socio-economic status. Memon et al., (2010) found out that families with high financial status regularly have more accomplishment in setting up their young youngsters for school since they commonly approach a full scope of assets to advance and bolster youthful children's improvement.

TABLE II SUPPORT AND INTEREST OF THE RESPONDENTS ( $\mathrm{N}=65)$

\begin{tabular}{|l|c|c|}
\hline & Frequency & Percentage \\
\hline \multicolumn{3}{|c|}{ A. Status of Parental Support } \\
\hline Supported & 15 & 23.00 \\
\hline Less supported & 49 & 75.00 \\
\hline Not supported & 1 & 2.00 \\
\hline \multicolumn{3}{|c|}{ B. Extent of Interest } \\
\hline Interested & 18 & 28.00 \\
\hline Less interested & 44 & 68.00 \\
\hline Not interested & 3 & 4.00 \\
\hline \multicolumn{3}{|c|}{ Age (in years) } \\
\hline 20 - 25 & 5 & 7.69 \\
\hline 15 - 19 & 60 & 92.31 \\
\hline \multicolumn{2}{|c|}{ D. Hours Spent in Studying in a Week } \\
\hline 1 to 3 hours & 16 & 25.00 \\
\hline Less than an hour & 49 & 75.00 \\
\hline Average : & 1.25 & \\
\hline \multicolumn{3}{|c|}{} \\
\hline
\end{tabular}

As exposed in the table III, the results suggested how significant it was for the students to feel the support, love, and care of their parents in the course of finishing their studies. It showed that the respondents' parents could have been failed to let their children feel that their parents are always there to support them all thru out their academic journey. The simple gestures of asking how the school was or talking how were the things going in the students' studies may mean a lot for them to feel motivated to go on. The parent-child discussion or conversations concerning schoolrelated activities, programs, near- and long-term school plans and other academic issues were already forms of parental support that had produced a strong positive association with improved students' academic achievement 
and reduced problematic behavior. Also, the table disclosed that out of 65 respondents, 44 or 68 percent of those were less interested in finishing their secondary education. A person's interest was of high factor that affected whatever he/she wanted to achieve. As highlighted by Long et al., (2007), the cultural minorities intrinsic motivation and interest were so significantly low. This almost always pushed them to discontinue their studies for they felt the extreme inferiority towards the majority in the society. Indigenous people's feeling of being less of a person was a result of the marginalization and discrimination in the outside community (Molintas, 2004). Based on the data, most of the respondents claimed they usually studied up to 1 hour a week only when they were still in school. The trend showed that the shorter the hours spent in studying, the higher the risk of leaving from school. Pathania et al., (2005) established that the cultural minority students were not so devoted in improving their study habits due to being less interested in finishing their studies for they seemed to be content with the lives and found the belongingness inside their community.

B. Reasons for Leaving the School: The table IV below was composed of 10 statements that covered the respondents perceived reasons for leaving from school in terms of family factors. The results of the data gathered were presented in the table.

TABle Iv Reasons For Leaving The School As To Family Factors ( $\mathrm{N}=65)$

\begin{tabular}{|l|l|l|c|}
\hline S. No. & \multicolumn{1}{|c|}{ Indicators } & Mean & Description \\
\hline 1. & The number of my siblings make it difficult to finish my studies & 3.09 & Moderately Agree \\
\hline 2. & I am mandated to look after my brother/sisters. Thus, I do not attend my class. & 3.11 & Moderately Agree \\
\hline 3. & I could have quickly finished my assignments had my parents were well educated & 3.85 & Agree \\
\hline 4. & Finishing my study is more achievable had my parents attended higher education & 3.77 & Agree \\
\hline 5. & I am not interested in going to school for my parents' job is not stable & 3.29 & Moderately Agree \\
\hline 6. & It is easy to finish my study if my parents have a good job & 3.52 & Agree \\
\hline 7. & It is always difficult to listen to class discussions because of my hungry stomach & 1.85 & Disagree \\
\hline 8. & I have frequent absences because of not having an allowance. & 4.56 & Strongly Agree \\
\hline 9. & My parents do not care to ask me about my problems and concerns I have. & 1.77 & Strongly Disagree \\
\hline 10. & My parents do not express their love and support for my studies. & 1.89 & Strongly Disagree \\
\hline & Overall Mean : & 3.07 & Moderately Agree \\
\hline
\end{tabular}

TABle V Reasons For LeAVIng The School As To Personal Factors ( $\mathrm{N}=65)$

\begin{tabular}{|l|l|c|c|}
\hline S. No. & \multicolumn{1}{|c|}{ Indicators } & Mean & Description \\
\hline 1. & My age is no longer appropriate to the grade level I am into & 3.11 & Moderately Agree \\
\hline 2. & My age makes me hesitant to continue studying & 2.51 & Disagree \\
\hline 3. & Male Badjaos are preferred to help the family earn a living & 4.20 & Strongly Agree \\
\hline 4. & Female Badjaos are allowed to marry early as part of the tradition, rather than to finish their studies & 2.95 & Moderately Agree \\
\hline 5. & I usually do not participate in the discussion and answering exercises & 2.92 & Moderately Agree \\
\hline 6. & $\begin{array}{l}\text { I am an easy-go-lucky person who does not care about excellent academic } \\
\text { performance }\end{array}$ & 2.60 & Disagree \\
\hline 7. & I do not regularly study my lessons or assignment & 2.65 & Moderately Agree \\
\hline 8. & I do not study harder to improve my academic performance & 2.37 & Disagree \\
\hline 9. & I am not deserving to be given good grades in the class & 3.58 & Agree \\
\hline 10. & I am not confident of getting higher scores in an examination or quiz. & 2.75 & Moderately Agree \\
\hline & Overall Mean : & 2.96 & Moderately Agree \\
\hline
\end{tabular}

As reflected in the table IV, the statement "I have habitual absences because of not having allowance" had the highest weighted mean of 4.56, which means that the respondents had faced difficulty in attending their classes because of not having enough financial support in defraying the expenses incurred in traveling from home to school and vice versa; buying foods to eat during recess time and other incidental expenditures that may arise therefrom. This implicated that students' attendance in school could be associated with the parent's income.

This result is similar with the findings of Thompson and Mazer (2012) that claimed, students, whose parents' income was considerably higher, were more likely to go on with studies for they could pay the school and non-academic related expenses. Similarly, Pong and Ju (2000) found out 
that high parental income allowed them to provide more resources to support their children's education, including access to better quality schools, private tuitions and more support for learning within the home. During the financial crisis, the schooling of the children became the first casualty in poor households.

This only means that the parental income pulled down the overall weighted mean of family factors to highlight its significance as a possible determinant why the respondents discontinued studying.

TABle Vi Reasons For Leaving The School As To Social InTEgRation Factors ( $=65)$

\begin{tabular}{|c|c|c|c|}
\hline S. No. & Indicators & Mean & Description \\
\hline 1. & Teachers are available to answer my academic questions & 3.97 & Agree \\
\hline 2. & Teachers know my strong academic points & 3.72 & Agree \\
\hline 3. & Teachers make me feel that I belong in the class & 3.65 & Agree \\
\hline 4. & Teachers are sensitive to my differences in learning styles & 3.69 & Agree \\
\hline 5. & Teachers provide me feedback on my academic growth and progress & 3.17 & Moderately Agree \\
\hline 6. & Teachers ask me how things are going at home. & 3.20 & Moderately Agree \\
\hline 7. & I have useful personal contacts with my teachers & 2.89 & Moderately Agree \\
\hline 8. & Teachers provide me emotional support and advice. & 3.20 & Moderately Agree \\
\hline 9. & Teachers respect my being as a member of an indigenous tribe & 3.37 & Moderately Agree \\
\hline 10. & Teachers praise me if I do something good & 3.66 & Agree \\
\hline 11. & Other students approach me to work together on tasks & 4.28 & Strongly Agree \\
\hline 12. & I collaborate well with my fellow students. & 3.80 & Agree \\
\hline 13. & My classmates and I go to the library together & 3.17 & Moderately Agree \\
\hline 14. & My classmates invite me to study with them in the group & 3.75 & Agree \\
\hline 15. & My classmates provide me peer tutorial once I do not fully understand the lesson & 3.14 & Moderately Agree \\
\hline 16. & I know everyone in the class & 3.80 & Agree \\
\hline 17. & My fellow students ask me to hang out with them & 2.74 & Moderately Agree \\
\hline 18. & My classmates care to know my problems & 3.60 & Agree \\
\hline 19. & My classmates respect my being as a Badjao & 4.05 & Agree \\
\hline \multirow[t]{2}{*}{20.} & I have plenty of friends in the classroom or campus & 3.38 & Moderately Agree \\
\hline & Overall Mean : & 3.51 & Agree \\
\hline
\end{tabular}

These data from the table VI suggested that the Badjao respondents had a positive learning environment in the classroom that supposedly made them feel motivated to persist in their studies. These figures showed that the interaction between teachers and the respondents on school or academic-related matters was not a determinant why the respondents became school leavers. Though personal matters need to be set aside, but in the contexts of the teacher-student relationship. The lack of simple academic integration or good interaction between teachers and students of personal-related matters more often bore negative consequences, especially for ethnic minorities.

The table VII below presented the perceived reasons for leaving from school in terms of program implementation by the concerned agencies. The program implemented was measured to ascertain whether it was one of the
As revealed in the table $\mathrm{V}$, the statement "Male Badjaos are preferred to help the family earn a living" had the highest weighted mean of 4.20 , which means that the respondents had acknowledged that as part of the culture and tradition in their households, males were encouraged by the parents to help augment the family's income. This became a determinant why the male Badjaos were most likely to drop out of school. Severiens and Wolff (2008) found out that members of the minority who left school were linked to cultural orientation. 
Table ViI Reasons For Leaving The School As To Program Implementation ( $\mathrm{N}=65$ )

\begin{tabular}{|c|c|c|}
\hline Indicators & Mean & Description \\
\hline \multicolumn{3}{|c|}{ A. The National Commission for Indigenous People (NCIP) is not consistent in implementing the: } \\
\hline 1. Educational Assistance Program & 2.38 & Moderately Agree \\
\hline 2. Financial Assistance Program & 2.26 & Disagree \\
\hline \multicolumn{3}{|c|}{ B. The Department of Social Welfare and Development (DSWD) is not consistent in implementing the: } \\
\hline 1. Conditional Cash Transfer Program & 1.91 & Disagree \\
\hline 2. Livelihood for the Indigenous People Program & 1.85 & Disagree \\
\hline \multicolumn{3}{|c|}{ C. The Department of Education (DepEd) is not consistent in implementing the: } \\
\hline 1. Alternative Learning System & 2.91 & Moderately Agree \\
\hline 2. Localization and Contextualization of Instructional Materials & 3.58 & Agree \\
\hline 3. Indigenous People Cultural Awareness Program & 2.18 & Disagree \\
\hline 4. Values Formation Program & 2.18 & Disagree \\
\hline Overall Mean : & 2.41 & Disagree \\
\hline
\end{tabular}

Furthermore, the statement "The Department of Education (Dep. Ed) is not consistent in implementing the: Alternative Learning System (ALS); Localization and Contextualization of Instructional Materials; Indigenous People Cultural Awareness Program; and Values Formation Program" had the average weighted mean of 2.72. This denotes that the respondents had still disagreed of the abovementioned statement. Such disagreement could indicate that they still had found the program implementation to be still not significant to become a determinant why they had gone from school.Generally, perceived reasons of leaving from school in terms of program implementation of the concerned agencies had the average weighted mean of 2.41 only indicated that the program implementation of the concerned agencies was not a determinant why the respondents became school leavers.

C. Test of Significant Relationship: The table VIII below presented the results of multiple regressions between the perceived reasons for leaving from school and the profile of family factors. This was done to determine the correlation between the respondent's family factor profile and their actual perceptions on family factors as perceived reasons for leaving from school.

Table ViII Relationship Between Reason Of LEAVing From School And Family Factors Profile

\begin{tabular}{|l|c|c|c|c|c|c|}
\hline \multicolumn{7}{|c|}{ Regression Statistics } \\
\hline Multiple R & \multicolumn{7}{|c|}{0.1928} \\
\hline R Square & \multicolumn{7}{|c|}{0.0372} \\
\hline Adjusted R Square & \multicolumn{7}{|c|}{1.4525} \\
\hline Standard Error & \multicolumn{7}{|c|}{65} \\
\hline Observations & \multicolumn{7}{|c|}{ Results } \\
\hline & Coef & Std Error & t Stat & P-value & Significance & Resule \\
\hline Intercept & 2.19 & 0.99 & 2.20 & 0.03 & Significant & Ho rejected \\
\hline Family Size & 0.07 & 0.14 & 0.48 & 0.63 & Not Significant & Ho accepted \\
\hline Parents Support & 0.26 & 0.80 & 0.33 & 0.74 & Not Significant & Ho accepted \\
\hline
\end{tabular}

As reflected in the table VIII, the computed multiple $\mathrm{R}$ is 0.1928 , which signified that there was a negligible positive correlation between the relationship of the predicted and observed values of the reasons why respondents leave from school. Moreover, 0.61 percent of the variance in the values of the perceived was explained by the family size and parents' support.

The test for this regression coefficient revealed that family size with t-value of 0.48 and $p$-value of 0.63 implied that the family size is not a significant determinant for the respondents to leave from school. The parents' support with t-value of 0.33 and p-value of 0.74 connoted that parental support is not a significant determinant for the respondents to leave from school. Generally, the respondent's family factor profile and their actual perceptions on family factors as perceived reasons for leaving from school were not correlated.

Comparably, Feinstein and Peck (2008) found that family size and parental support were not significant determinants of dropping-out from school among secondary school students. Nonetheless, this finding was contradictory with the findings of Thompson and Mazer (2012) which found 
that the higher the family size and the less the parental school especially if the parents got a low income. support, the students were most-likely to drop-out from

Table Ix Relationship Between Reason Of Leaving From School And Personal Factors Profile

\begin{tabular}{|l|c|c|c|c|c|c|}
\hline \multicolumn{7}{|c|}{ Regression Statistics } \\
\hline Multiple R & \multicolumn{7}{c|}{0.2877} \\
\hline R Square & \multicolumn{7}{c|}{0.0828} \\
\hline Adjusted R Square & \multicolumn{7}{|c|}{1.4411} \\
\hline Standard Error & \multicolumn{7}{|c|}{65} \\
\hline Observations & \multicolumn{7}{|c|}{ Pesults } \\
\hline & Coef & Std Error & t Stat & P-value & Significance & Resule \\
\hline Intercept & 1.77 & 2.47 & 0.72 & 0.48 & Not Significant & Ho accepted \\
\hline Age & 0.19 & 0.12 & 1.62 & 0.11 & Not Significant & Ho accepted \\
\hline Interest & 0.07 & 0.35 & 0.21 & 0.83 & Not Significant & Ho accepted \\
\hline Study Habits & -0.26 & 0.32 & -0.83 & 0.41 & Not Significant & Ho accepted \\
\hline Self-esteem & -0.84 & 0.56 & -1.51 & 0.14 & Not Significant & Ho accepted \\
\hline
\end{tabular}

As reflected in the table IX, the computed multiple $\mathrm{R}$ is 0.2877 , which implied that there was a negligible positive correlation between the relationship of the predicted and observed values of the perceived reason of leaving from school.Moreover, 2.16 percent of the variance of the values of the perceived reasons were accounted for by the age, interest, study habits and self-esteem of the respondents. The result of this regression coefficient exposed that the age with t-value of 1.62 and p-value of 0.11 ; interest (academic achievement) with t-value of 0.21 and p-value of 0.83 ; study habits with t-value of -0.83 and p-value of 0.4 ; and selfesteem with $\mathrm{t}$-value of 1.51 and $\mathrm{p}$-value of 0.14 indicated that those are not significant determinants for the respondents to leave from school. Besides, the respondent's personal factor profile and their actual perceptions on personal factors as perceived reasons for leaving from school were not correlated.
Janosz et al., (2014) corroborated partly the results above, as one of the findings of his study pointed out that the age and study habits were less likely to cause the students to drop out. Further, in the same study, he emphasized that academic interests and self-esteem were found to be of significant value for the students to cope up with academic stresses and challenges. The higher the self-esteem and the academic interest, the lesser the probability of dropping out of school.

These findings were supported with the findings of Komarraju and Nadler (2013), which discovered that the students who have high self-efficacy and interest of continuing their studies, they were most likely to succeed and be less likely to leave from school.

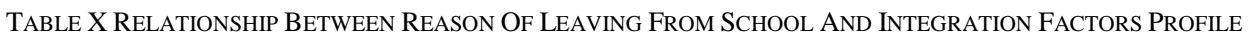

\begin{tabular}{|c|c|c|c|c|c|c|}
\hline \multicolumn{7}{|c|}{ Regression Statistics } \\
\hline Multiple R & \multicolumn{6}{|c|}{0.3216} \\
\hline R Square & \multicolumn{6}{|c|}{0.1034} \\
\hline Adjusted R Square & \multicolumn{6}{|c|}{0.0436} \\
\hline Standard Error & \multicolumn{6}{|c|}{1.4248} \\
\hline \multirow[t]{2}{*}{ Observations } & \multicolumn{6}{|c|}{65} \\
\hline & Coef & Std Error & t Stat & P-value & Significance & Results \\
\hline Intercept & 0.50 & 1.15 & 0.43 & 0.67 & Not Significant & Ho accepted \\
\hline Formal Academic Integration & 0.41 & 0.34 & 1.22 & 0.23 & Not Significant & Ho accepted \\
\hline Informal Academic Integration & 0.65 & 0.32 & 2.02 & 0.05 & Significant & Ho rejected \\
\hline Formal Social Integration & -0.01 & 0.29 & -0.03 & 0.98 & Not Significant & Ho accepted \\
\hline Informal Social Integration & 0.27 & 0.32 & 0.84 & 0.41 & Not Significant & Ho accepted \\
\hline
\end{tabular}

As reflected in the table $\mathrm{X}$, the computed multiple $\mathrm{R}$ is 0.3216 , which implied that there was a negligible positive correlation between the relationship of the perceived reason of leaving from school and the respondents' personal factors profile. Other than that, 4.36 percent of the variance in the values of the perceived reasons were attributed to Formal 
Academic Integration, Informal Academic Integration, Formal Social Integration, and Informal Social Integration. The result of this regression coefficient exposed that the age with $\mathrm{t}$-value of 1.62 and $\mathrm{p}$-value of 0.11 ; interest (academic achievement) with t-value of 0.21 and $p$-value of 0.83 ; study habits with t-value of -0.83 and p-value of 0.4 ; and selfesteem with t-value of 1.51 and $\mathrm{p}$-value of 0.14 indicated that those are not significant determinants for the respondents to leave from school. Besides, the respondent's factor profile and their actual perceptions on personal factors as perceived reasons for leaving from school were not correlated.

\section{CONCLUSION}

Based on the findings of the study, the study concluded that the Badjao respondents had perceived that personal and family factors could be the determinants why they had left school. Further, integration and program implementation were not associated with why they had left school. The respondents' profile and their perceived reasons for leaving school had no significant relationship. Lastly, the respondents perceived reasons for leaving from school, and the extent of program implementation was found to be of no significant relationship still.

\section{REFERENCES}

[1] Ainsworth, M., Beegle, K., \& Koda, G. (2005). The impact of adult mortality and maternal deaths on primary schooling in North-Western Tanzania. The Journal of Development Studies, 41(3), 412-439. Retrieved from http://bit.ly/2VbJ5Lt

[2] Brookfield, S. D. (2005). The power of critical theory for adult learning and teaching. The Adult Learner, 85. Retrieved from http://bit.ly/2V9fYbO

[3] Charon, J. M., \& Cahill, S. (1979). Symbolic interactionism: An introduction, an interpretation, an integration, 133. Englewood Cliffs, NJ: Prentice-hall. Retrieved from http://bit.ly/307s8FM

[4] Considine, G., \& Zappalà, G. (2002). The influence of social and economic disadvantage in the academic performance of school students in Australia. Journal of Sociology, 38(2), 129-148. Retrieved from http://bit.ly/2HeeRTd

[5] Drayton, B., \& Prins, E. (2009). The enactment of hegemony through identity construction: Insights from the presentation of self in everyday life. Retrieved from http://bit.ly/2VUXdgy

[6] Eamon, M. K. (2005). Social-demographic, school, neighbourhood, and parenting influences on the academic achievement of Latino young adolescents. Journal of Youth and Adolescence, 34(2), 163174. Retrieved from http://bit.ly/2VS2xkJ

[7] Eloundou, E. P. (Dec 2000). Trade-off between family size and education. Africa Notes, Retrieved from http://bit.ly/2VfQdGx

[8] Feinstein, L., \& Peck, S. C. (2008). Unexpected pathways through education: Why do some students not succeed in school and what helps others beat the odds? Journal of Social Issues, 64(1), 1-20. Retrieved from http://bit.ly/2VXOBWk

[9] Fry, R. (2003). Hispanic youth dropping out of US schools: Measuring the challenge. Retrieved from http://bit.ly/2VqJjmY

[10] Grant, M. J., \& Hallman, K. K. (2008). Pregnancy -related school dropout and prior school performance in KwaZulu -Natal, South Africa. Studies in Family Planning, 39(4), 369-382. Retrieved from http://bit.ly/2Vs1Mzo
[11] Hohepa, M., Schofield, G., \& Kolt, G. S. (2006). Physical activity: What do high school students think? Journal of Adolescent Health, 39(3), 328-336. Retrieved from http://bit.ly/2VrM1bH

[12] Ho Sang, D. (2010). Racial propositions: Ballot initiatives and the making of postwar California, 30, Univ of California Press. Retrieved from http://bit.ly/2Vd2lrQ

[13] Janosz, M., Archambault, I., Morizot, J., \& Pagani, L. S. (2008). School engagement trajectories and their differential predictive relations to dropout. Journal of Social Issues, 64(1), 21-40. Retrieved from http://bit.ly/2vPevgu

[14] Komarraju, M., \& Nadler, D. (2013). Self-efficacy and academic achievement: Why do implicit beliefs, goals, and effort regulation matter? Learning and Individual Differences, 25, 67-72. Retrieved from http://bit.ly/2DZI17J

[15] Lareau, A. (2003). Unequal childhoods. Berkeley. Retrieved from http://bit.ly/2VVvwnY

[16] Long, J. F., Monoi, S., Harper, B., Knoblauch, D., \& Murphy, P. K. (2007). Academic motivation and achievement among urban adolescents. Urban Education, 42(3), 196-222. Retrieved from http://bit.ly/2HbDaBf

[17] Macalandag, R. E. (2009). Otherizing the Badjao: A spatial imagery of state exclusion and societal otherization. A Research Paper in Partial Fulfillment of the Requirements for Obtaining the Degree of Masters of Arts in Development Studies. International Institute of Social Studies, The Hague. Retrieved from http://bit.ly/2VnRkJk

[18] Memon, G. R., Joubish, F. M., \& Khurram, A. M. (2010). Impact of parental socioeconomic status on students' educational achievements at secondary schools of district Malir, Karachi. Middle-East Journal of Scientific Research, 6(6), 678-687. Retrieved from http://bit.ly/ $2 \mathrm{VoNAr} 3$

[19] Molintas, J. M. (2004). The Philippine indigenous peoples' struggle for land and life: Challenging legal texts. Ariz. J. Int'l \& Comp. L., 21, 269. Retrieved from http://bit.ly/2VqHSF5

[20] Monks, C. P., \& Smith, P. K. (2006). Definitions of bullying: Age differences in understanding of the term, and the role of experience. British Journal of Developmental Psychology, 24(4), 801-821. Retrieved from http://bit.ly/2Has7s2

[21] Pathania, R., Kaur, P. R. A. V. E. E. N., \& Pathania, P. A. W. A. N. (2005). Problems faced by the tribal students in education. Indian Journal of Social Work, 66(3), 323. Retrieved from http://bit.ly/ 2JDiWTV

[22] Pong, S. L., \& Ju, D. B. (2000). The effects of change in family structure and income on dropping out of middle and high school. Journal of Family Issues, 21(2), 147-169. Retrieved from http://bit.ly/307FFNG

[23] Reyes, C. M., Mina, C. D., \& Asis, R. D. (2017). Inequality of opportunities among ethnic groups in the Philippines (No. 2017/154). WIDER Working Paper. Retrieved from http://bit.ly/2VnWBRb

[24] Rigby, K. (2004). Addressing bullying in schools: Theoretical perspectives and their implications. School Psychology International, 25(3), 287-300. Retrieved from http://bit.ly/2VSDu0V

[25] Rogoff, B. (2003). The cultural nature of human development. Oxford University Press. Retrieved from http://bit.ly/2HbYlih

[26] Severiens, S., \& Wolff, R. (2008). A comparison of ethnic minority and majority students: Social and academic integration, and quality of learning. Studies in Higher Education, 33(3), 253-266. Retrieved from http://bit.ly/2DXx4Du

[27] Smedley, A., \& Smedley, B. D. (2005). Race as biology is fiction, racism as a social problem is real: Anthropological and historical perspectives on the social construction of race. American Psychologist, 60(1), 16. Retrieved from http://bit.ly/2HcRQBo

[28] Thompson, B., \& Mazer, J. P. (2012). Development of the parental academic support scale: Frequency, importance, and modes of communication. Communication Education, 61(2), 131-160. Retrieved from http://bit.ly/2DT9Aj5

[29] Young, R. J. (2005). Colonial desire: Hybridity in theory, culture, and race. Routledge. Retrieved from http://bit.ly/2vMEgOj 